Polymer Journal, Vol. 39, No. 5, pp. 442-447 (2007)

(C) 2007 The Society of Polymer Science, Japan

\title{
A Negative Type Photosensitive Polymer Based on Poly(naphthylene ether), a Cross-Linker, and a Photoacid Generator with Low Dielectric Constant
}

\author{
Kousuke TsuchiYA, Yuji ShIBASAKI, and Mitsuru UEDA ${ }^{\dagger}$ \\ Department of Organic and Polymeric Materials, Graduate School of Science and Engineering, \\ Tokyo Institute of Technology, 2-11-1 O-okayama, Meguro-ku, Tokyo 152-8552, Japan
}

(Received January 11, 2007; Accepted February 10, 2007; Published March 23, 2007)

\begin{abstract}
A novel negative-working thermally stable photosensitive polymer based on poly(naphthylene ether), a cross-linker hexa(methoxymethyl)melamine, and a photoacid generator (5-propylsulfonyl-oxyimino- $5 \mathrm{H}$-thiophen-2-ylidene)-(2-methylphenyl)acetonitrile. Poly(naphthylene ether) was prepared via the oxidative coupling polymerization of 4,4'-bis(1-naphthyloxy)-2,2'-dimethylbiphenyl. This photosensitive polymer showed a high sensitivity $\left(D_{0.5}\right)$ of $6.0 \mathrm{~mJ} \mathrm{~cm}^{-2}$ and a high contrast $\left(\gamma_{0.5}\right)$ of 5.2 , when it was exposed to a $436 \mathrm{~nm}$ light, post-exposure baked at $140{ }^{\circ} \mathrm{C}$ for $5 \mathrm{~min}$, and developed with toluene. A negative image featuring $20 \mu \mathrm{m}$ line and space patterns was obtained on a film exposed to $20 \mathrm{~mJ} \mathrm{~cm}^{-2}$ of visible light at $436 \mathrm{~nm}$ by the contact-printed mode. The resulting polymer film had the low dielectric constant of 2.8 and high thermal stability. [doi:10.1295/polymj.PJ2006213]

KEY WORDS Low Dielectric Constant / Poly(naphthylene ether) / Oxidative Coupling

Polymerization / Negative Tone / Photosensitive Polymer / High Sensitivity /
\end{abstract}

Thermally stable photosensitive polymers represented by photosensitive polyimides (PSPIs) have been widely used as protection and insulation layers in the manufacturing of semiconductors. ${ }^{1-6}$ On the continuous miniaturization of the very large scale integration circuit (VLSI), low dielectric materials are essential to prevent the interconnect delay of electrical signal in the high-density and high-frequency multilayer printed circuit. ${ }^{7}$ The polyimides (PIs) with dielectric constants $(\varepsilon)$ of 3.5 is inadequate for next generation interlayer dielectrics, furthermore, the moisture absorption of PIs is disadvantageous as low $\varepsilon$ materials (low- $k$ materials). Consequently the matrix polymer should be replaced with the polymers possessing a low $\varepsilon$.

As substitutes of PIs, there are several matrix polymers such as poly(benzoxazole)s (PBOs) ${ }^{8-10}$ and poly(phenylene ether)s (PPEs), ${ }^{11}$ which are successfully applied to the photosensitive polymers. Poly(2,6-dihydroxy-1,5-naphthylene) (PDHN) exhibits low $\varepsilon$ of 2.8, and have been applied to both negative- ${ }^{12}$ and positive-type ${ }^{13}$ photosensitive polymers because of moderate dissolution behavior in an alkaline developer. However, the moisture absorption of PDHN is still considerable concern due to the presence of polar hydroxyl groups.

Recently, thermally stable organic polymers with a large free volume have been proposed as the next generation low- $k$ dielectrics. ${ }^{14}$ We have also reported a series of poly(naphthylene ether)s (PNEs) via oxidative coupling polymerization for organic low- $k$ mate- rials. ${ }^{15-17}$ The kinked binaphthyl backbone produces a molecular size free volume in polymers, and decreases effectively the molecular density. Therefore PNEs show a lower $\varepsilon$ without sacrificing high thermal stability and high mechanical strength. Moreover, PNEs having no polar groups in the aromatic backbone can be expected to reduce moisture absorption.

This article reports a new photosensitive polymer consisting of PNE, hexa(methoxymethyl)melamine (CYMEL) as a cross-linker, and (5-propylsulfonyloxyimino-5H-thiophen-2-ylidene)-(2-methylphenyl)acetonitrile (PTMA) as a photoacid generator. The properties of resulting patterned polymer films are also described.

\section{EXPERIMENTAL}

\section{Materials.}

Nitrobenzene was distilled under reduced pressure over calcium hydride and then stored under nitrogen atmosphere. A photoacid generator PTMA was kindly donated by Ciba Specialty Chemicals K.K., and used without further purification. Other reagents and solvents were used as received.

Synthesis of 4,4'-Bis(1-naphthyloxy)-2,2'-dimethylbiphenyl (1).

To the solution of $4,4^{\prime}$-dihydroxy-2,2'-dimethylbiphenyl $(5.00 \mathrm{~g}, 10.7 \mathrm{mmol})$ in toluene $(30 \mathrm{~mL})$ was added potassium carbonate $(2.96 \mathrm{~g}, 21.4 \mathrm{mmol})$, and heated at $150^{\circ} \mathrm{C}$ for $2 \mathrm{~h}$ to remove water with a

${ }^{\dagger}$ To whom correspondence should be addressed (Tel/Fax: +81-3-5734-2127, E-mail: mueda@ polymer.titech.ac.jp). 
dean-stark apparatus. After the formation of the potassium salt, toluene was removed by heating at $150^{\circ} \mathrm{C}$, and the solution was cooled to room temperature. To this salt were added copper powder $(0.034 \mathrm{~g}, 0.535$ $\mathrm{mmol})$, quinoline $(0.15 \mathrm{~mL}, 0.535 \mathrm{mmol})$ and 1-bromonaphthalene $(3.3 \mathrm{~mL}, 23.5 \mathrm{mmol})$, followed by heating the mixture at $200{ }^{\circ} \mathrm{C}$ for $24 \mathrm{~h}$ under nitrogen atmosphere. After cooling this solution to room temperature, the reaction mixture was extracted with dichloromethane, and washed subsequently with $1 \mathrm{M}$ $\mathrm{HCl}$. The solvents were evaporated, and the residual oil was purified by silica gel column chromatography (toluene/hexane $1 / 2$ in volume ratio). A yellow solid 1 was obtained after drying at $150^{\circ} \mathrm{C}$ in vacuo. The yield was $4.6 \mathrm{~g}(62 \%)$. mp 59-60 ${ }^{\circ} \mathrm{C} .{ }^{1} \mathrm{H}$ NMR $\left(\mathrm{CDCl}_{3}\right): \delta=2.06(\mathrm{~s}, 6 \mathrm{H}), 6.89(\mathrm{dd}, 2 \mathrm{H}), 6.99(\mathrm{~d}$, $2 \mathrm{H}), 7.03(\mathrm{~d}, 2 \mathrm{H}), 7.08(\mathrm{~d}, 2 \mathrm{H}), 7.41(\mathrm{t}, 2 \mathrm{H}), 7.52(\mathrm{~m}$, $4 \mathrm{H}), 7.63(\mathrm{~d}, 2 \mathrm{H}), 7.88(\mathrm{~m}, 2 \mathrm{H}), 8.26 \mathrm{ppm}(\mathrm{m}, 2 \mathrm{H})$. ${ }^{13} \mathrm{C}$ NMR $\left(\mathrm{CDCl}_{3}\right): \delta=20.1,113.4,115.6,119.7$, 122.1, 123.2, 125.8, 125.9, 126.6, 126.9, 127.8, 130.9, 134.9, 136.0, 138.1, 153.2, 156.8 ppm. IR(KBr): 1234 (C-O), 1573 and $1600(\mathrm{Ar}-\mathrm{H}), 3050 \mathrm{~cm}^{-1}(\mathrm{Ar}-\mathrm{H})$. Anal. Calcd for $\mathrm{C}_{34} \mathrm{H}_{26} \mathrm{O}_{2}$ : C 87.52\%; $\mathrm{H} 5.62 \%$. Found: C $87.99 \%$; H $5.95 \%$.

\section{Preparation of Poly(4,4'-bis(1-naphthyloxy)-2,2'-di- methylbiphenyl) (2).}

To the solution of $\mathbf{1}(4.6 \mathrm{~g}, 9.9 \mathrm{mmol})$ in nitrobenzene $(25 \mathrm{~mL})$ was added iron (III) chloride $(4.0 \mathrm{~g}, 25$ mmol) under nitrogen atmosphere. The reaction mixture was stirred for $1.5 \mathrm{~h}$ at room temperature and poured into methanol. The precipitate was collected, dissolved in a small amount of chloroform, filtered, and reprecipitated in methanol. The white polymer was obtained $(4.1 \mathrm{~g}, 89 \%)$. ${ }^{1} \mathrm{H} \mathrm{NMR}\left(\mathrm{CDCl}_{3}\right): \delta=$ $2.06(\mathrm{~s}, 6 \mathrm{H}), 6.89(\mathrm{dd}, 2 \mathrm{H}), 6.99(\mathrm{~d}, 2 \mathrm{H}), 7.03(\mathrm{~d}$, $2 \mathrm{H}), 7.08(\mathrm{~d}, 2 \mathrm{H}), 7.41(\mathrm{t}, 2 \mathrm{H}), 7.52(\mathrm{~m}, 4 \mathrm{H}), 7.63$ $(\mathrm{d}, 2 \mathrm{H}), 7.88(\mathrm{~m}, 2 \mathrm{H}), 8.26 \mathrm{ppm}(\mathrm{m}, 2 \mathrm{H}) .{ }^{13} \mathrm{C}$ NMR $\left(\mathrm{CDCl}_{3}\right): \delta=20.2,112.3,116.1,120.2,122.2,125.7$, 125.8, 126.6, 126.7, 128.0, 131.0, 133.3, 134.3, 136.3, 138.2, 153.1, $156.6 \mathrm{ppm}$. IR(KBr): 1230 (C-O), 1589 and $1600(\mathrm{Ar}-\mathrm{H}), 3058 \mathrm{~cm}^{-1}(\mathrm{Ar}-\mathrm{H})$. Anal. Calcd for $\mathrm{C}_{34} \mathrm{H}_{24} \mathrm{O}_{2}$ : C 87.90\%; H 5.21\%. Found: C $88.23 \%$; H $5.58 \%$.

\section{Dissolution Rate.}

Polymer 2 was dissolved in chlorobenzene at a concentration of $10 \mathrm{wt} \%$, followed by addition of CYMEL and PTMA. The $3.0 \mu \mathrm{m}$ thickness of polymer films were obtained by spin-casting the solution at $1000 \mathrm{rpm}$ for $30 \mathrm{~s}$ on a silicon wafer. These films were pre-baked at $100{ }^{\circ} \mathrm{C}$ for $1 \mathrm{~min}$, exposed to a filtered super-high pressure mercury lamp at $436 \mathrm{~nm}$ (g-line), and post-exposure baked at stated temperature for 5 min. The dissolution rate $\left(\AA \mathrm{s}^{-1}\right)$ of the film thick- ness was determined from the changes in the film thickness before and after the development with toluene.

\section{Photosensitivity.}

A 3.0- $\mu \mathrm{m}$-thick photosensitive polymer film on a silicone wafer was exposed to the light of $436 \mathrm{~nm}$ with changing a dose, post-exposure baked at $140{ }^{\circ} \mathrm{C}$ for $5 \mathrm{~min}$, and then developed with toluene for $80 \mathrm{~s}$. A characteristic curve was obtained by plotting a normalized film thickness as a function of exposure dose (unit: $\mathrm{mJ} \mathrm{cm}^{-2}$ ).

\section{Model Reaction.}

To the solution of $1(10 \mathrm{mg}, 0.021 \mathrm{mmol})$ and CYMEL ( $1 \mathrm{mg}, 0.0025 \mathrm{mmol})$ in $0.4 \mathrm{~mL}$ of deutrated dimethylsulfoxide (DMSO- $d_{6}$ ) was added a catalytic amount of methanesulfonic acid in a NMR tube, then the mixture was heated at $140^{\circ} \mathrm{C}$ for $1 \mathrm{~h}$. Before and after the reaction, the ${ }^{1} \mathrm{H}$ NMR of the sample was measured at $40^{\circ} \mathrm{C}$.

\section{Measurement.}

Infrared spectra were recorded on a Horiba FT-720 spectrophotometer. ${ }^{1} \mathrm{H}$ and ${ }^{13} \mathrm{C}$ NMR spectra were obtained on a BRUKER DPX-300 spectrometer at ${ }^{1} \mathrm{H}$, $300 \mathrm{MHz}$ and ${ }^{13} \mathrm{C}, 75 \mathrm{MHz}$. Deuterated chloroform or DMSO- $d_{6}$ was used as a solvent with tetramethylsilane as an internal standard. Number- and weightaverage molecular weights $\left(M_{\mathrm{n}}\right.$ and $\left.M_{\mathrm{w}}\right)$ were determined by a gel permeation chromatograph (GPC) on a Jasco GULLIVER 1500 system equipped with a polystyrene gel column (Plgel $5 \mu \mathrm{m}$ MIXED-C) eluted with chloroform at a flow rate of $1.0 \mathrm{~mL} \mathrm{~min}^{-1}$ calibrated by standard polystyrene samples. The film was spin-coated on a silicone wafer from the polymer solution in chlorobenzene, and the film thickness was measured by Veeco Instrument Dektak ${ }^{3}$ surface profiler. The scanning electron microscopic image (SEM) was taken by a Technex Lab. Tiny-SEM 1540 with $5 \mathrm{kV}$ accelerating voltage. Thermal analysis was performed on a Seiko EXSTAR 6000 TG/DTA 6300 thermal analyzer at a heating rate of $10^{\circ} \mathrm{C} \mathrm{min}^{-1}$ for thermogravimetry (TG) and a Seiko EXSTAR 6000 DSC 6200 at a heating rate of $10^{\circ} \mathrm{C} \mathrm{min}^{-1}$ for differential scanning calorimetry (DSC) under nitrogen. Refractive indices of polyimide films formed on quartz substrates were measured at a wavelength of $1320 \mathrm{~nm}$ at room temperature with a Metricon model PC-2000 prism coupler. Using linearly-polarized laser light with parallel (TE: transverse electric) and perpendicular (TM: transverse magnetic) polarization to the film plane, the in-plane $\left(n_{\mathrm{TE}}\right)$ and out-of-plane $\left(n_{\mathrm{TM}}\right)$ refractive indices and the film thickness of the samples were determined. 


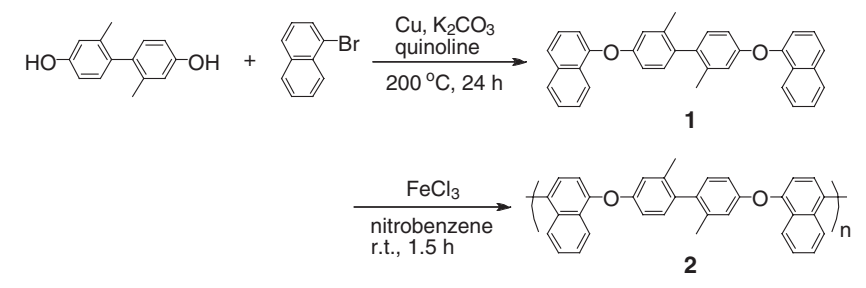

Scheme 1. Syntheses of monomer 1 and polymer 2.

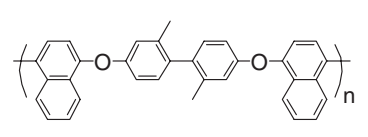

2

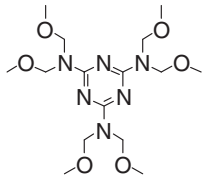

CYMEL

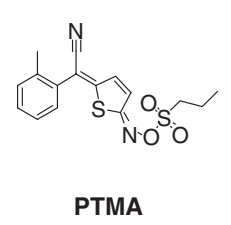

PTMA
Scheme 2. Composition of photosensitive polymer.

\section{RESULTS AND DISCUSSION}

\section{Synthesis of Matrix Poly(naphthylene ether) 2.}

The monomer (1) was prepared from 4,4'-dihydroxy-2,2'-dimethylbiphenyl and 1-bromonaphthalene by the Ullmann reaction, then converted to the polymer (2) by the oxidative coupling polymerization using iron (III) chloride as an oxidant (Scheme 1). The structure of the obtained polymer was determined by IR, ${ }^{1} \mathrm{H}$ NMR and ${ }^{13} \mathrm{C}$ NMR spectroscopy. The number averaged molecular weight $\left(M_{\mathrm{n}}\right)$ and polydispersity index of the resulting polymer were 28,000 and 2.7 , respectively. The polymer showed good solubility in common solvents such as toluene, chloroform, and tetrahydrofuran, and provided a robust film by spin casting.

\section{Photosensitive Polymer Formulation.}

Judging from no absorption above $400 \mathrm{~nm}$ in the UV-visible spectrum of $\mathbf{2}$, this polymer can be used as a matrix for a photosensitive polymer system using g-line $(436 \mathrm{~nm}$ light). The photosensitive polymer was formulated by mixing 2 with a cross-linker and a photoacid generator (PAG). We selected hexa(methoxymethyl)melamine (CYMEL) as a cross-linker because the aromatic rings of $\mathbf{2}$ can react with a carbocation formed from CYMEL ${ }^{18}$ in the presence of an acid. On the other hand, PTMA ${ }^{19}$ that has a strong absorption at $436 \mathrm{~nm}$ was used as a PAG (Scheme 2).

\section{Lithographic Evaluation.}

To clarify the dissolution behavior of the exposed and unexposed areas at $436 \mathrm{~nm}$ light, the post-exposure baking (PEB) temperature was studied. The dissolution rate was estimated by measuring the film thickness after developing in toluene, and the results

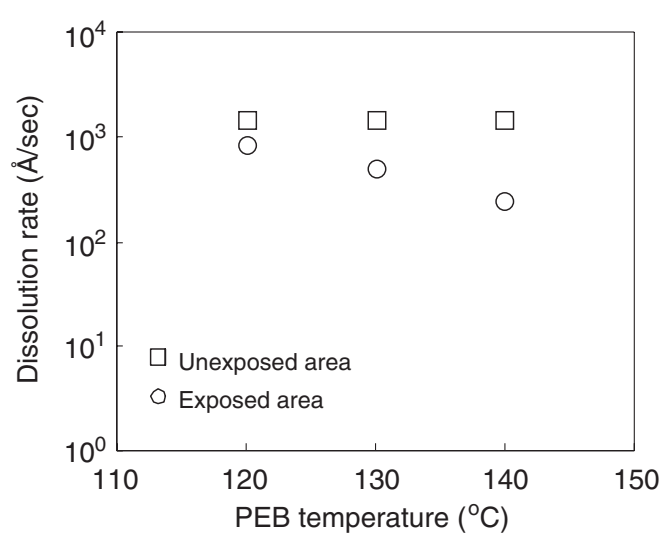

Figure 1. Effect of PEB temperature on dissolution rate of the polymer film consisting of 2 (85 wt \%), CYMEL (10 wt \%), and PTMA (5 wt \%). The film was irradiated $20 \mathrm{~mJ} \mathrm{~cm}^{-2}$ of g-line, post baked at each temperature for $5 \mathrm{~min}$, and developed with toluene.

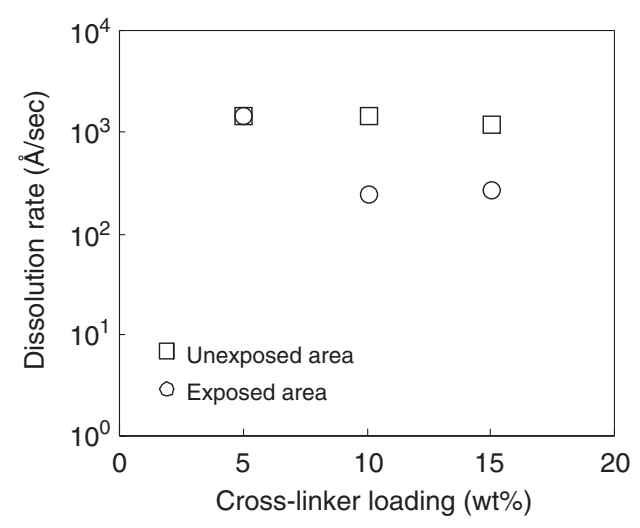

Figure 2. Effect of amount of CYMEL on dissolution rate of the polymer film consisting of 2, CYMEL, and PTMA (5 wt \%). The film was irradiated $20 \mathrm{~mJ} \mathrm{~cm}^{-2}$ of g-line, post baked at $140^{\circ} \mathrm{C}$ for $5 \mathrm{~min}$, and developed with toluene.

are shown in Figure 1. The most effective PEB temperature to give the high dissolution contrast between the exposed and unexposed area is $140^{\circ} \mathrm{C}$. Next, the effect of the cross-linker loading was investigated (Figure 2). Little dissolution contrast is observed when 5 wt \% CYMEL was added. On the other hand, a higher loading of CYMEL achieves the larger dissolution contrast, which saturates at a $10 \mathrm{wt} \%$ loading. However, some extent of decrease in film thickness was observed at even a $15 \mathrm{wt} \%$ CYMEL loading probably because the cross-linker with an aromatic ring (CYMEL) is less reactive than that with a hydroxyl group (e.g., 4,4'-methylenebis[2,6-di(hydroxymethyl)]phenol ${ }^{11,12}$ ).

Therefore, the effect of PTMA loading was studied at a $10 \mathrm{wt} \%$ CYMEL loading as shown in Figure 3. The decrease of the film thickness is improved with a higher PTMA loading, and the exposed area be- 


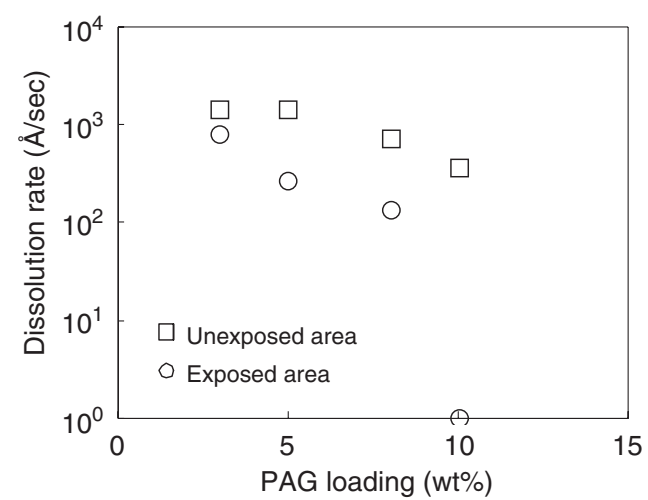

Figure 3. Effect of amount of PTMA on dissolution rate of the polymer film consisting of 2, CYMEL (10 wt \%), and PTMA. The film was irradiated $20 \mathrm{~mJ} \mathrm{~cm}^{-2}$ of g-line, post baked at $140{ }^{\circ} \mathrm{C}$ for $5 \mathrm{~min}$, and developed with toluene.

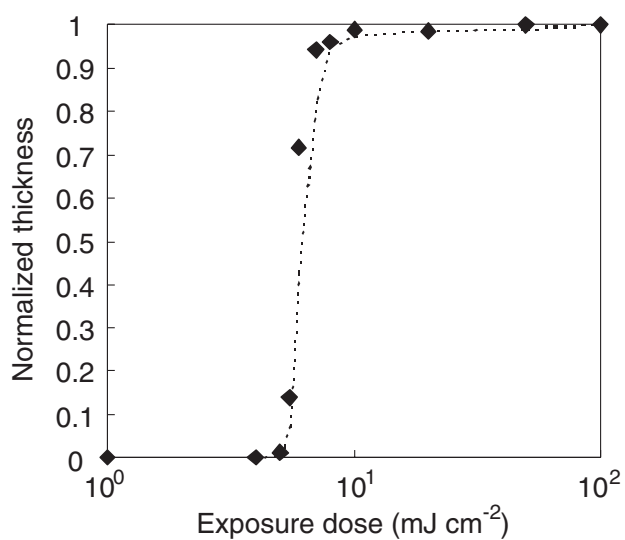

Figure 4. Characteristic photosensitivity curve of the polymer film consisting of 2 (80 wt \%), CYMEL (10 wt \%), and PTMA (10 wt \%). The film (thickness: $3.0 \mu \mathrm{m}$ ) was irradiated the g-line, post baked at $140^{\circ} \mathrm{C}$ for $5 \mathrm{~min}$, and developed with toluene.

comes completely insoluble in the developer at a $10 \mathrm{wt} \%$ PTMA loading. On the other hand, the dissolution rate of the unexposed area is slightly decreased at higher PTMA loadings because small amount of PTMA probably decomposed due to high PEB temperature nearly close to decomposition temperature of PTMA. ${ }^{19}$ Based on these preliminary optimizations, the photosensitive polymer system consisting of 2 (80 wt \%), CYMEL (10 wt \%) and PTMA (10 wt \%) was formulated. The sensitivity curve as shown in Figure 4 was obtained at the optimized conditions, from which the sensitivity $\left(D_{0.5}\right)$ and the contrast $\left(\gamma_{0.5}\right)$ of this photosensitive polymer system were determined to be $6.0 \mathrm{~mJ} \mathrm{~cm}^{-2}$ and 5.2 , respectively. Figure 5 shows a scanning electron micrograph image of the line-and-space patterning obtained by a contact-printing mode using this system. The clear negative-tone pattern with a $20 \mu \mathrm{m}$ resolution is observed.

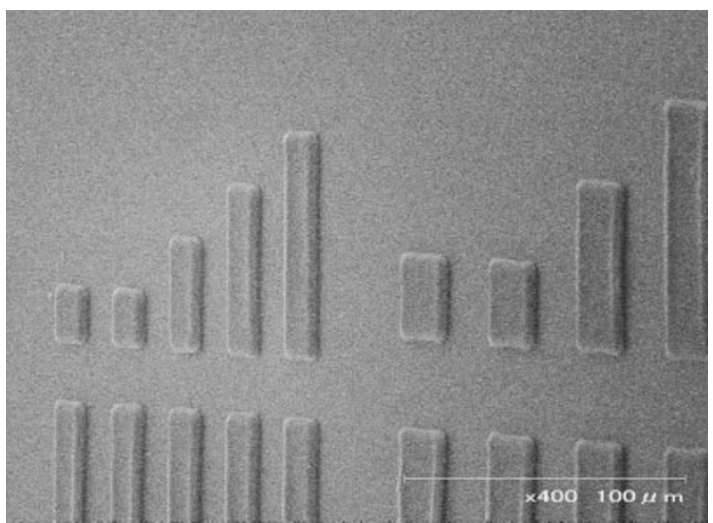

Figure 5. A scanning electron micrograph image of the contact-printed film consisting of 2 (80 wt \%), CYMEL (10 wt \%), and PTMA $(10 \mathrm{wt} \%)$. The film was irradiated $20 \mathrm{~mJ} \mathrm{~cm}^{-2}$ of $\mathrm{g}$ line, post baked at $140^{\circ} \mathrm{C}$ for $5 \mathrm{~min}$, and developed with toluene.

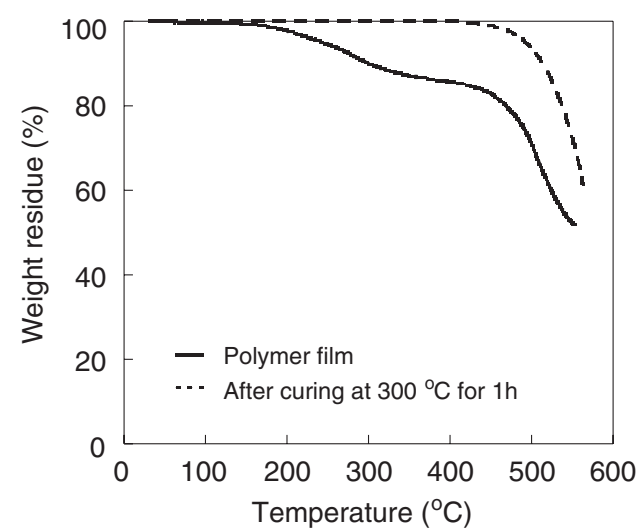

Figure 6. TGA curves of the polymer film consisting of 2 (80 wt \%), CYMEL (10 wt \%), and PTMA (10wt \%). The film was irradiated $20 \mathrm{~mJ} \mathrm{~cm}^{-2}$ of g-line, and post baked at $140{ }^{\circ} \mathrm{C}$ for $5 \mathrm{~min}$.

\section{Thermal Stability of Polymer Film.}

The solid line in Figure 6 shows TG curve of the polymer film consisting of 2, CYMEL, and PTMA after exposure of $10 \mathrm{~mJ} \mathrm{~cm}^{-2}$, followed by treatment of PEB at $140^{\circ} \mathrm{C}$ for $5 \mathrm{~min}$. The TG curve for the film after the curing at $300{ }^{\circ} \mathrm{C}$ for $1 \mathrm{~h}$ under nitrogen is shown as the dotted line. About the $15 \mathrm{wt} \%$ weight loss is observed over $200^{\circ} \mathrm{C}$, which is attributed to the decomposition of PTMA and the residue of CYMEL. The $5 \mathrm{wt} \%$ weight loss temperature of the cured film is $494^{\circ} \mathrm{C}$, which is coincident with that of the matrix polymer. Figure 7 shows a SEM image of a negative tone pattern after thermal treatment at $300^{\circ} \mathrm{C}$ for $1 \mathrm{~h}$ under nitrogen. No pattern collapse is observed comparing with Figure 5, although the film is slightly shrunk from 5.0 to $4.2 \mu \mathrm{m}$. These results indicate that the photosensitive polymer system shows high thermal stability through the lithographic process. 


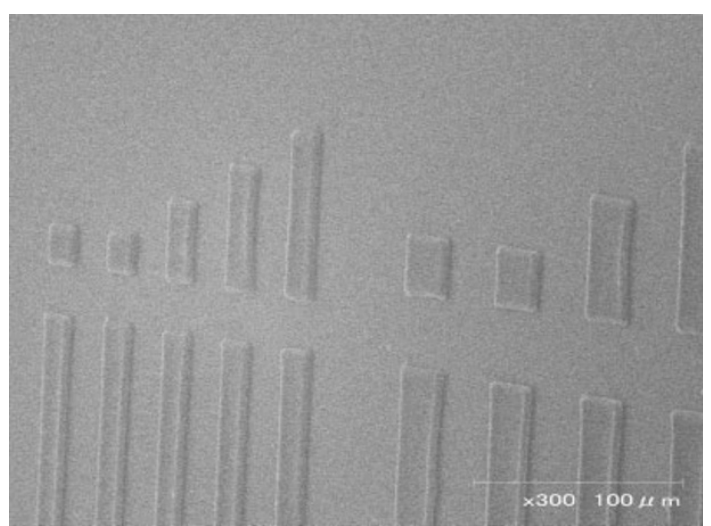

Figure 7. A scanning electron micrograph image of the contact-printed polymer film cured at $300{ }^{\circ} \mathrm{C}$ for $1 \mathrm{~h}$ under nitrogen atmosphere.

Table I. Refractive indices and dielectric constants of polymer films

\begin{tabular}{cccccc}
\hline film & $d(\mu \mathrm{m})^{\mathrm{a}}$ & $n_{\mathrm{TE}}{ }^{\mathrm{b}}$ & $n_{\mathrm{TM}^{\mathrm{c}}}$ & $n_{\mathrm{AV}}{ }^{\mathrm{d}}$ & $\varepsilon^{\mathrm{e}}$ \\
\hline $\begin{array}{c}\text { 2 } \\
\text { 2 with CYMEL }\end{array}$ & 5.0 & 1.647 & 1.621 & 1.638 & 2.68 \\
and PTMA & 4.0 & 1.689 & 1.646 & 1.674 & 2.80 \\
\hline
\end{tabular}

${ }^{\mathrm{a}}$ Film thickness. ${ }^{\mathrm{b}}$ The in-plane refractive indices. ${ }^{\mathrm{c}}$ The outof-plane refractive indices. ${ }^{\mathrm{d}}$ Average refractive indices;

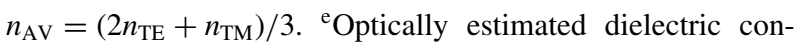
stant; $\varepsilon=1.0 n_{\mathrm{AV}}^{2}$.

\section{Refractive Index and Dielectric Constant.}

The $\varepsilon$ of the polymer film at $1 \mathrm{MHz}$ can be estimated from the refractive index $(n)$ of the film according to the modified Maxwell's equation, $\varepsilon \approx n^{2}$. The films of polymers on quartz were prepared by spin-casting from chlorobenzene, and then these films were dried at $150^{\circ} \mathrm{C}$ for $6 \mathrm{~h}$ under vacuum.

Table I summarizes the refractive indices and the optically estimated $\varepsilon$ of $\mathbf{2}$ and the resist film of $\mathbf{2}$, which was exposed to $10 \mathrm{~mJ} \mathrm{~cm}^{-2}$, post-baked at $100^{\circ} \mathrm{C}$ for $5 \mathrm{~min}$, developed with toluene at $25^{\circ} \mathrm{C}$, and cured at $300^{\circ} \mathrm{C}$ for $1 \mathrm{~h}$. The average refractive indices $\left(n_{\mathrm{AV}}\right)$ of the former and the latter were determined as 1.638 and 1.674 , respectively, which were translated into $\varepsilon$ of 2.68 and 2.80 , respectively. The $\varepsilon$ of the latter is slightly higher than that of the former due to the thermally decomposed residues of CYMEL and PTMA.

\section{Model Reaction for Cross-Linking Mechanism.}

The model reaction of $\mathbf{2}$ and CYMEL in the presence of an acid was carried out to understand the mechanism of a cross-linking reaction (Figure 8). To the solution of 1 and CYMEL in DMSO- $d_{6}$ was added a catalytic amount of methanesulfonic acid, and the mixture was heated at $140^{\circ} \mathrm{C}$ for $1 \mathrm{~h}$. The signal (b) (a) without methanesulfonic acid

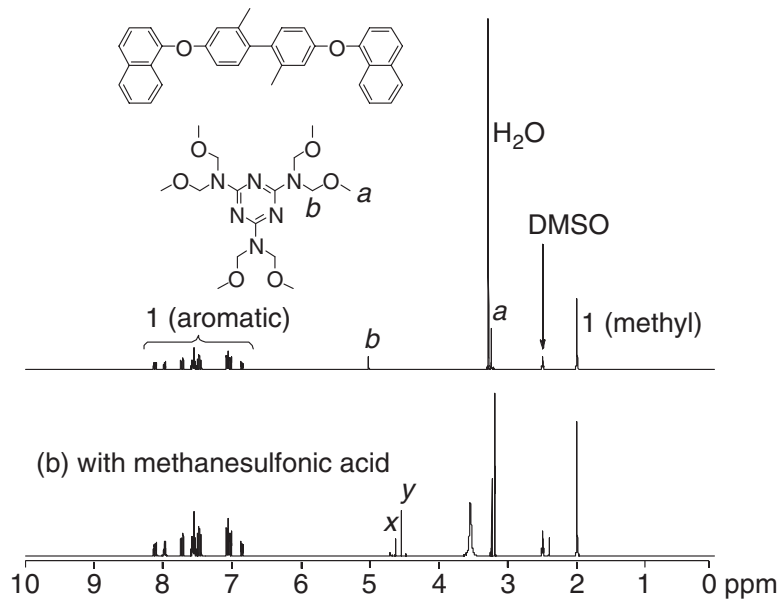

Figure 8. The ${ }^{1} \mathrm{H}$ NMR spectra of (a) $\mathbf{1}$ and CYMEL $\left(10 \mathrm{wt} \%\right.$ ), and (b) after heated at $140^{\circ} \mathrm{C}$ for $1 \mathrm{~h}$ in the presence of a catalytic amount of methanesulfonic acid in DMSO- $d_{6}$.

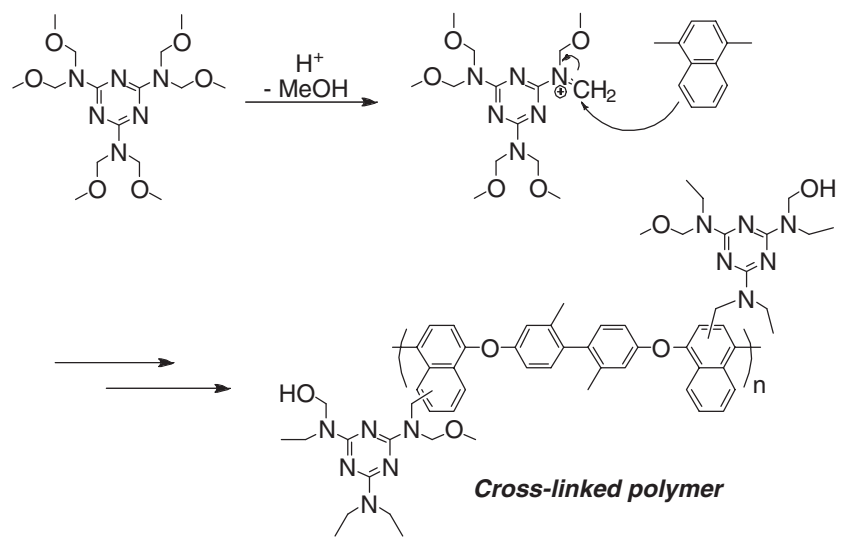

Scheme 3. Mechanism of cross-linking reaction.

assigned to the methylene protons of CYMEL at $5.02 \mathrm{ppm}$ completely disappears after heating in the presence of methanesulfonic acid, while two signals corresponding to the methylene protons appear at 4.54 and $4.62 \mathrm{ppm}$. The hydrolysis of methoxymethylamine moiety generates hydroxymethylamine corresponding to the signal (y). Therefore, the signal (x) is assumed to be the methylene protons reacted with aromatic rings of $\mathbf{1}$. The $\mathrm{C}$-alkylation of the methoxymethylamine moiety on aromatic rings occurred by heating with the acid as shown in Scheme 3, which converted soluble PNE into the insoluble cross-linked polymer.

\section{CONCLUSION}

A novel poly(naphthylene ether) 2 was prepared via the oxidative coupling polymerization of 4,4'-bis(1naphthyloxy)-2,2'-dimethylbiphenyl (1), which successfully formulated to a negative-type photosensitive 
polymer with a cross-linker CYMEL and a photoacid generator PTMA. This system showed a high sensitivity $\left(D_{0.5}\right)$ of $6.0 \mathrm{~mJ} \mathrm{~cm}^{-2}$ and a high contrast $\left(\gamma_{0.5}\right)$ of 5.2 , respectively, to give a clear negative tone lineand-space pattern with $20 \mu \mathrm{m}$ resolution. The resulting polymer film has the low dielectric constant and high thermal stability to withstand the upcoming demands for next generation devices.

\section{REFERENCES}

1. "Polyimide," M. K. Ghosh and K. L. Mittal, Ed., M. Dekker, New York, 1996, p121.

2. "Photosensitive Polyimide: Fundamental and Applications," K. Horie and T. Yamashita, Ed., Technomic, Lancasteer, 1995.

3. N. Yoda, Polym. Adv. Technol., 8, 215 (1997).

4. H. Seino, A. Mochizuki, O. Haba, and M. Ueda, J. Polym. Sci., Part A: Polym. Chem., 36, 2261 (1998).

5. Y. Watanabe, Y. Shibasaki, S. Ando, and M. Ueda, Polym. J., 37, 270 (2005).

6. K. Sakayori, Y. Shibasaki, and M. Ueda, Polym. J., 38, 1189 (2006).
7. G. Maier, Prog. Polym. Sci., 26, 3 (2001).

8. K. Fukukawa, Y. Shibasaki, and M. Ueda, Polym. J., 37, 74 (2005).

9. K. Fukukawa and M. Ueda, Polym. J., 38, 405 (2006).

10. F. Toyokawa, Y. Shibasaki, and M. Ueda, Polym. J., 37, 517 (2005).

11. K. Takeshi, K. Okuyama, Y. Ohba, and M. Ueda, J. Photopolym. Sci. Technol., 13, 345 (2000).

12. K. Tsuchiya, Y. Shibasaki, M. Suzuki, and M. Ueda, J. Polym. Sci., Part A: Polym. Chem., 42, 2235 (2004).

13. K. Tsuchiya, Y. Shibasaki, and M. Ueda, Polymer, 45, 6873 (2004).

14. T. M. Long and T. M. Swager, J. Am. Chem. Soc., 125, 14113 (2003).

15. K. Tsuchiya, Y. Shibasaki, S. Ando, and M. Ueda, Macromolecules, 37, 4794 (2004).

16. K. Tsuchiya, Y. Shibasaki, M. Aoyagi, and M. Ueda, Macromolecules, 39, 3964 (2006).

17. K. Tsuchiya and M. Ueda, Polym. J., 38, 956 (2006).

18. M. M. O'Toole, M. P. de Grandpre, and W. E. Feely, J. Electrochem. Soc., 135, 1026 (1988).

19. T. Asakura, H. Yamato, and M. Ohwa, J. Photopolym. Sci. Technol., 13, 223 (2001). 